\title{
Miglitol, an Anti-diabetic Drug, Inhibits Oxidative Stress-Induced Apoptosis and Mitochondrial ROS Over-Production in Endothelial Cells by Enhancement of AMP-Activated Protein Kinase
}

\author{
Chie Aoki ${ }^{1}$, Kunihiro Suzuki ${ }^{1, *}$, Kazunori Yanagi ${ }^{1}$, Hiroko Satoh ${ }^{1}$, Mai Niitani ${ }^{1}$, and Yoshimasa Aso ${ }^{1}$ \\ ${ }^{1}$ Department of Endocrinology and Metabolism, Dokkyo Medical University, Mibu, Tochigi 321-0293, Japan
}

Received May 8, 2012; Accepted August 26, 2012

\begin{abstract}
Endothelial dysfunction caused by oxidative stress plays a key role in atherogenesis. This study investigated whether the anti-diabetic drug miglitol, an $\alpha$-glucosidase inhibitor, which is currently available in clinical practice, can prevent endothelial cell apoptosis and whether it might restore impaired vascular relaxation under oxidative stress. The bEnd.3 cells, a microvascular endothelial cell line, were pre-treated with various concentrations of miglitol and then were incubated with $\mathrm{H}_{2} \mathrm{O}_{2}$ for $1-2 \mathrm{~h}$. Treatment of bEnd. 3 cells with miglitol resulted in the protection of cell viability, suppression of mitochondrial superoxide production, and DNA strand breakage under the oxidative stress. These effects of miglitol were associated with the activation of AMPactivated protein kinase (AMPK) and the phosphorylation of endothelial nitric oxide synthase (eNOS). In aortic rings with endothelium, acetylcholine (Ach)-induced relaxation was attenuated by $\mathrm{H}_{2} \mathrm{O}_{2}$. We found that this impaired relaxation was restored by acute treatment with miglitol. Compound $\mathrm{C}$, an AMPK inhibitor, inhibited the amelioration of vascular relaxations treated with miglitol. These results suggest that miglitol might protect against endothelial cells damage under oxidative stress via inhibition of endothelial cell apoptosis and mitochondrial superoxide production, which are mediated by the activation of AMPK and the phosphorylation of eNOS.
\end{abstract}

Keywords: miglitol, oxidative stress, endothelial cell, AMP-activated protein kinase (AMPK)

\section{Introduction}

Endothelial dysfunction signals a start of the atherosclerotic process (1) and is closely associated with the development of hypertension, hypercholesterolemia, diabetes mellitus, diabetic complications, and heart failure $(2,3)$.

Harmful reactive oxygen species (ROS) play a key role in development of endothelial dysfunction (4). Augmented formation of mitochondrial ROS appears to be one of the principal pathways of endothelial dysfunction in diabetes $(2,3,5,6)$.

$\alpha$-Glucosidase inhibitors ( $\alpha$-GIs) are anti-diabetic agents that improve postprandial hyperglycemia, one of the most common abnormalities in the early phase of type 2 diabetes $(7,8)$. Recently, miglitol $(N$-hydroxyethyl-

*Corresponding author. Kuni-s@dokkyomed.ac.jp Published online in J-STAGE on September 26, 2012 (in advance) doi: $10.1254 /$ jphs. $12108 \mathrm{FP}$ 1-deoxynojirimycin), a relatively new $\alpha$-GI, is clinically used in the treatment for patients with type 2 diabetes $(8$, 9). Miglitol has the unique property of being wellabsorbed, and it circulates in its original form (10). Some reports have demonstrated that the absorbed miglitol improves glucose metabolism, insulin sensitivity, and suppresses neointimal thickening of arterial wall in animals $(10-12)$. Thus, because of its anti-atherogenetic effects, miglitol may be a beneficial drug for the treatment of type 2 diabetes.

In the present study, therefore, we investigated whether miglitol could directly ameliorate or even prevent endothelial cells against apoptosis caused by ROS via the phosphorylation of endothelial nitric oxide synthase (eNOS), the activation of AMP-activated protein kinase (AMPK), and the inhibition of ROS overproduction by itself. Furthermore, we also examined whether miglitol might improve impaired vascular relaxation under oxidative stress using the aortic rings from rats. 


\section{Material and Methods}

\section{Materials}

Miglitol was supplied by Sanwa Kagaku Kenkyusho Co., Ltd. (Nagoya). Hydrogen peroxide $\left(\mathrm{H}_{2} \mathrm{O}_{2}\right)$ was purchased from Sigma (St. Louis, MO, USA).

\section{Cell culture}

The bEnd. 3 microvascular endothelial cell line was purchased from the European Collection of Cell Cultures (ECACC, Salisbury, UK) and was cultured in a $37^{\circ} \mathrm{C}$, $5 \% \mathrm{CO}_{2}$, humidified chamber, with $1 \mathrm{~g} / 1$ glucose $(5.5$ $\mathrm{mM}$ ) containing Dulbecco's modified Eagle's medium (DMEM) with 10\% fetal bovine serum (Invitrogen, Carlsbad, CA, USA), 2 mM glutamine, $100 \mathrm{IU} / \mathrm{ml}$ penicillin, $100 \mu \mathrm{g} / \mathrm{ml}$ streptomycin, and $1 \%$ non-essential amino acids (Sigma).

\section{Measurement of cell viability}

The mitochondrial-dependent reduction of 3-(4,5dimethylthiazol-2-yl)-2,5-diphenyltetrazolium bromide (MTT) to formazan was used to measure mitochondrial respiration, as an indicator of cell viability $(13,14)$. MTT was added at the last $1 \mathrm{~h}$ during the treatment. Dimethylsulfoxide at $150 \mu \mathrm{M}$ was added to each well at room temperature. The absorbance was read at $570 \mathrm{~nm}$ in a SpectraMax M2 Multi-detection Reader (Molecular Devices Corp., Sunnyvale, CA, USA) (14).

\section{Western blotting}

Whole-cell lysates were made using RIPA buffer with EDTA (Boston BioProduct, Ashland, MA, USA) with a protein protease inhibitor cocktail. Equal amounts of protein lysates (determined by the Pierce Micro BCA Protein Assay) were separated using 8\% - 12\% SDSPAGE gels and transferred to a $0.45-\mu \mathrm{m}$ nitrocellulose (Bio-Rad, Hercules, CA, USA). The membrane was blocked with 5\% low fat milk in PBS or Tris-buffered saline (TBS) containing 0.05\% Tween-20 and subsequently incubated with the primary antibody at a suitable dilution overnight at $4^{\circ} \mathrm{C}$. Primary antibodies for AMPK, P-AMPK, eNOS, P-eNOS, Akt, and P-Akt were from Cell Signaling (Beverly, MA, USA); for PAR, from TREVIGEN (Gaithersburg, MD, USA); and for $\alpha$-tubule, from Sigma. Immunoreactive proteins were visualized by G:Box chemi XT (Syngene, Frederick, MD, USA). The intensity of western blot signals was quantified by densitometry using Image analysis software (GeneSnap, Syngene).

\section{Measurement of mitochondrial ROS production}

MitoSox red (Invitrogen), a mitochondrion-specific hydroethidine-derivative fluorescent dye, was used to assess mitochondrial $\mathrm{O}_{2}^{-}$production in situ $(15,16)$. In brief, after treatment, cells were washed with PBS and loaded with $5 \mu$ of staining solution (in DMEM) for 30 $\min$ at $37^{\circ} \mathrm{C}$. Cells were washed and $100 \mu \mathrm{l}$ PBS was added. Fluorescence reading was performed by flow cytometry (Merck Millipore, Billerica, MA, USA).

\section{Quantitation of DNA strand breaks}

DNA strand breaks were detected with a single-cell gel electrophoresis assay (Comet assay; Trevigen, Gaithersburg, MD, USA) according to the manufacturer's instructions (17).

The mean length of the DNA tail was determined by measuring 20 cells for each condition.

\section{Measurement of nitrite and nitrate levels}

NO production within a monolayer of bEnd.3 was measured as previously reported (18). After various incubation times, nitrite and nitrate levels $\left(\mathrm{NO}_{2}{ }^{-}\right.$and $\left.\mathrm{NO}_{3}{ }^{-}\right)$ in the medium were measured using an automated $\mathrm{NO}$ detection/high-performance liquid chromatography system (ENO10; Eicom, Kyoto).

\section{Measurement of isometric force in the vascular rings}

Organ chamber experiments were performed as previously described (19). The animals were anesthetized with pentobarbital and killed by exsanguinations. Thoracic rings from Sprague-Dawley rats were cleared of adhering periadventitial fat and cut into $3-4 \mathrm{~mm}$ in width. Segments of thoracic aorta were mounted vertically between two hooks in an organ bath filled with warmed (to $37^{\circ} \mathrm{C}$ ) and oxygenated $\left(95 \% \mathrm{O}_{2} / 5 \% \mathrm{CO}_{2}\right)$ Krebs' solution $(\mathrm{pH}$ 7.4) of the following composition: $118 \mathrm{mM} \mathrm{NaCl}, 4.7$ $\mathrm{mM} \mathrm{KCl}, 1.2 \mathrm{mM} \mathrm{KH}_{2} \mathrm{PO}_{4}, 1.2 \mathrm{mM} \mathrm{MgSO}_{4}, 2.5 \mathrm{mM}$ $\mathrm{CaCl}_{2}, 25 \mathrm{mM} \mathrm{NaHCO}_{3}$, and $11.7 \mathrm{mM}$ glucose. Isometric tension was measured with force transducers (TB-651T; Nihon Kohden, Tokyo). A tension of $1 \mathrm{~g}$ was applied, and the rings were allowed to equilibrate for $60 \mathrm{~min}$. Fresh Krebs' solution was provided at 10-min intervals. The rings were then pre-contracted with phenylephrine $\left(10^{-7} \mathrm{M}\right)$, after which the concentration-response curve to acetylcholine (Ach) $\left(10^{-9}\right.$ to $\left.10^{-5} \mathrm{M}\right)$ was obtained. To abolish endothelial-dependent relaxation, the rings were exposed to $\mathrm{H}_{2} \mathrm{O}_{2}$ for $60 \mathrm{~min}$ before repeating the second response to pheylephrine. To investigate whether miglitol treatment could improve endothelial function in rings challenged by $\mathrm{H}_{2} \mathrm{O}_{2}$, after the first response to phenylephrine, the rings were exposed to $1 \mathrm{mM}$ miglitol in the presence and absence of $\mathrm{H}_{2} \mathrm{O}_{2}$ for $60 \mathrm{~min}$. An AMPK inhibitor, Compound C (C.C) (EMD Millipore, Darmstadt, Germany), was applied to the chamber 30 min before the addition of miglitol. The present experiments were reviewed and approved by the Committee on 
Ethics of Animal Experiments. The investigation conforms to the Guide for the Care and Use of Laboratory Animals published by the US National Institute of Health.

\section{Measurement of VCAM-1 and ICAM-1 mRNA expres- sion}

For quantitative measurement of mRNA, $2 \mu \mathrm{g}$ total RNA was treated with DNase I for 15 min and subsequently used for cDNA synthesis. Reverse transcription (RT) was performed using a SuperScript preamplification system (Invitrogen) with random oligonucleotide primers. The following primers were used: VCAM-1 forward primer, 5'-CCCAAGGATCCAGAGATTCA-3' and reverse primer, 5'-TAAGGTGAGGGTGGCATTT C-3'; ICAM-1 forward primer, 5'-CAGATGCCGACC CAGGAGAG-3' and reverse primer, 5'-ACAGACTT CACCACCCCGATG-3'. A typical reaction $(50 \mu \mathrm{l})$ was performed using 1/50 of RT-generated complementary DNA and $200 \mathrm{nM}$ primer in $1 \times$ SYBR Green RealTime Master Mix (Toyobo, Tokyo) buffer. The PCRs with the cDNA were performed in a LineGene system (BioFlux, Tokyo) under the following conditions: $95^{\circ} \mathrm{C}$ for $5 \mathrm{~min}$, 40 cycles at $95^{\circ} \mathrm{C}$ for $15 \mathrm{~s}, 60^{\circ} \mathrm{C}$ for $15 \mathrm{~s}$, and $72^{\circ} \mathrm{C}$ for $30 \mathrm{~s}$.

\section{Statistical analysis}

Data are expressed as the mean \pm S.E.M. Statistical comparisons between groups were performed by using ANOVA followed by Tukey's post hoc test.

\section{Results}

Miglitol reduces endothelial cell injury in response to $\mathrm{H}_{2} \mathrm{O}_{2}$

Changes in the cell viability in response to $\mathrm{H}_{2} \mathrm{O}_{2}$, using the MTT reduction method, are depicted in Fig. 1. The MTT method showed the deterioration of indicative cell viability and pretreatment with miglitol dose-dependently protected against this alteration.

Miglitol dose-dependently existed cytoprotective effects against oxidative stress by $\mathrm{H}_{2} \mathrm{O}_{2}$

ROS production increased after treatment with $\mathrm{H}_{2} \mathrm{O}_{2}$. Pre-treatment with miglitol $(100-500 \mu \mathrm{M})$ for $24 \mathrm{~h}$ decreased cellular ROS production (Fig. 2). Miglitol also reduced DNA injury (Fig. 3A) and the activation of the nuclear enzyme poly (ADP-ribose) polymerase (PARP) (Fig. 3B), which is known to be downstream of mitochondrial ROS formation. We observed that these effects of miglitol were partially abolished by the AMPK inhibitor, C.C (Fig. 3: A and B).

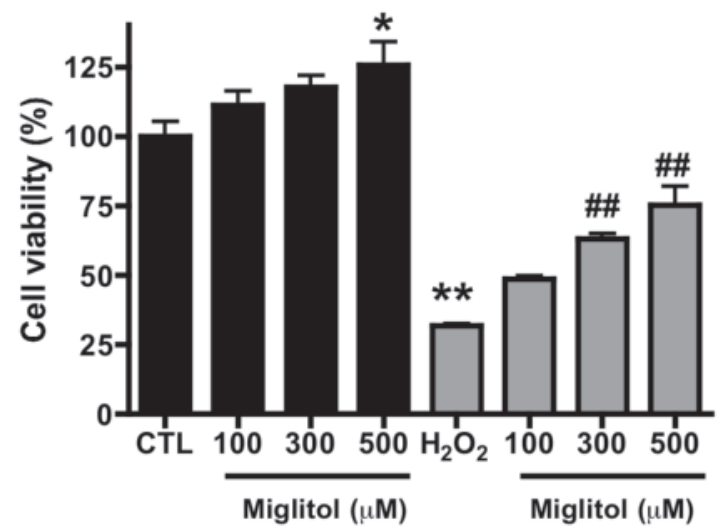

Fig. 1. Miglitol attenuates the bEnd.3 cell injury in response to $\mathrm{H}_{2} \mathrm{O}_{2}$. Confluent bEnd. 3 cell cultures were pre-treated with different doses of miglitol for $24 \mathrm{~h}$ and then exposed to $\mathrm{H}_{2} \mathrm{O}_{2}(300 \mu \mathrm{M})$ for $1 \mathrm{~h}$. Cell viability was determined by the MTT assay. There was a significant deterioration of the cell viability parameters after $\mathrm{H}_{2} \mathrm{O}_{2}$ treatment, compared to the untreated control cells (CTL) $(* * P<0.01)$, and the pre-treatment with miglitol dose-dependently protects against the alterations by $\mathrm{H}_{2} \mathrm{O}_{2}\left({ }^{\# \#} P<0.01\right)$. High concentration of miglitol ameliorates cell viability $(* P<0.05)$. Data are shown as the mean \pm S.E.M. values of $n=12$ wells collected from $n=3$ experiments performed on 3 different experimental days.

Miglitol activates AMPK and induces eNOS activity and NO production in endothelial cells

Treatment of bEnd.3 cells with miglitol resulted in time-dependent activation of AMPK, as monitored by phosphorylation of AMPK (Thr-172). Miglitol also increased Akt phosphorylation (Ser-473) and eNOS phosphorylation (Ser-1177) and its activation (Fig. 4A). Moreover, we found that eNOS phosphorylation caused by treatment with miglitol for 5 min was significantly suppressed by treatment with C.C, an AMPK inhibitor, (Fig. 4A). In contrast, AICAR, an activator of AMPK, induced AMPK phosphorylation (by $1254 \% \pm 80.3 \%$ compared to the control sample, at 5 min after treatment) and eNOS phosphorylation (by $237 \% \pm 3.4 \%$ compared to the control, at $5 \mathrm{~min}$ after treatment) as measured by the In Cell Western Assay (Li-Cor BioScience, Lincoln, NE, USA) (20). To evaluate NO production, we also measured the concentration of bioactive $\mathrm{NO}$ in the cellular supernatant (measured by $\mathrm{NO}_{2}^{-}$and $\mathrm{NO}_{3}^{-}$levels, Fig. 4B). Examination of the time course showed both miglitol and AICAR induced an appreciable increase in NO production over the course for $8 \mathrm{~h}$. As shown in Fig. $4 \mathrm{~B}$, an increased NO production by miglitol was markedly attenuated owing to the presence of C.C.

\section{Miglitol inhibits VCAM-1 and ICAM-1 mRNA expression and improves endothelial function in rats \\ Incubation with $\mathrm{H}_{2} \mathrm{O}_{2}$ in endothelial cells for $6 \mathrm{~h}$ ap- preciably induced ICAM-1 and VCAM-1 gene expres-}



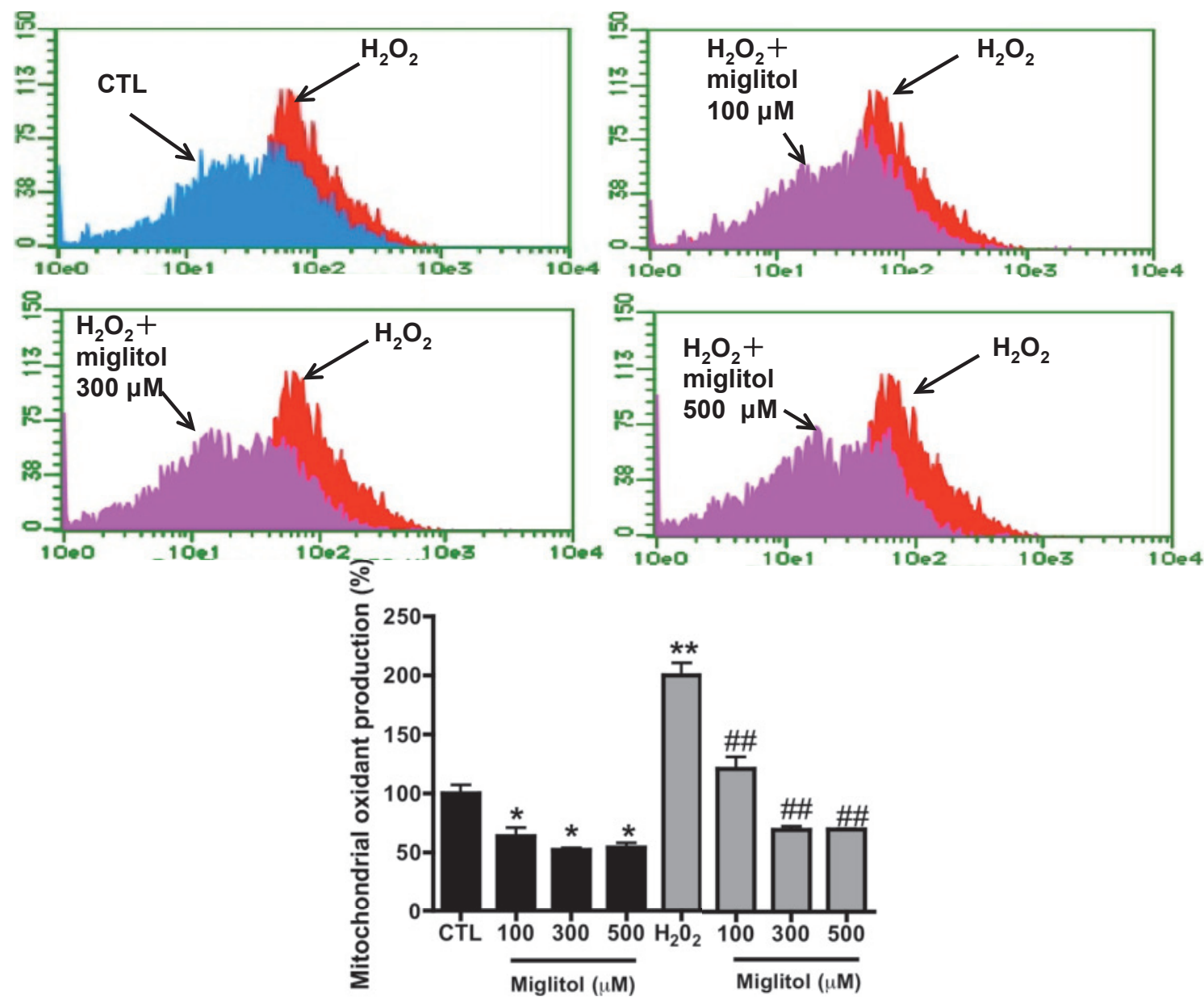

Fig. 2. Miglitol reduces mitochondrial superoxide production in response to $\mathrm{H}_{2} \mathrm{O}_{2}$ in bEnd. 3 cells. Confluent bEnd. 3 cultures were pre-treated for $24 \mathrm{~h}$ with different doses of miglitol and were then subjected to treatment with $\mathrm{H}_{2} \mathrm{O}_{2}(500 \mu \mathrm{M})$ for $2 \mathrm{~h}$. Mitochondrial superoxide production was measured by the MitoSox Red method. Miglitol afforded a concentration-dependent and significant suppression of superoxide production in the presence or absence of $\mathrm{H}_{2} \mathrm{O}_{2}$. Data are shown as the mean \pm S.E.M. values. $* P<0.05,{ }^{* *} P<0.01$ vs. CTL, ${ }^{\#} P<0.01$ vs. $\mathrm{H}_{2} \mathrm{O}_{2} ; \mathrm{n}=4$.

sion. This induction was dose-dependently suppressed by the treatment with miglitol (Fig. 5A).

In vitro incubation of rat aortic rings in the Krebs solution containing $\mathrm{H}_{2} \mathrm{O}_{2}$ resulted in an impairment of Achinduced (endothelium-dependent) relaxations (21), which was prevented by miglitol treatment (Fig. 5B). On the other hand, the protective effect of miglitol was antagonized and inhibited by the incubation with C.C for $1 \mathrm{~h}$.

Then we examined the effect of miglitol on the transactivation of NF- $\kappa$ B increased by $\mathrm{H}_{2} \mathrm{O}_{2}$. A dose-dependent decrease in NF- $\kappa \mathrm{B}$ activation was observed after treatment with miglitol (K. Suzuki et al., unpublished data).

\section{Discussion}

The present study demonstrated that miglitol, an $\alpha$-GI, not only suppresses postprandial hyperglycemia in vivo, but also significantly inhibits endothelial cell apoptosis and mitochondrial ROS overproduction in vitro. Indeed, we observed that miglitol has cytoprotective effects using the MTT reduction method: it attenuates mitochondrial membrane depolarization, ROS overproduction, and improves endothelial dysfunction via the activation of the AMPK pathway. This study is the first to show that miglitol reduces endothelial cells apoptosis induced by oxidative stress via a decrease in mitochondrial ROS overproduction. These findings are important for the treatment of diabetes mellitus since there is substantial evidence indicating that diabetes mellitus is one of the most crucial risk factors for atherosclerosis. Although the precise mechanisms are still unclear, the formation of ROS in endothelial cells is one of the most important factors in the first step of pathogenesis of diabetic vascular diseases such as coronary artery disease, peripheral 
A
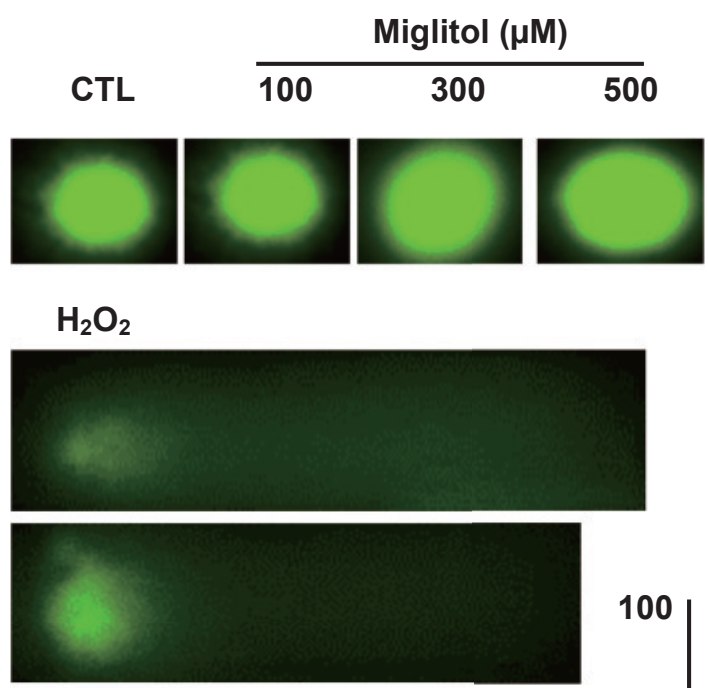

100

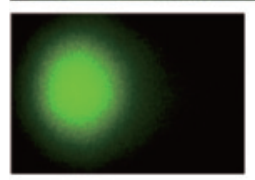

300
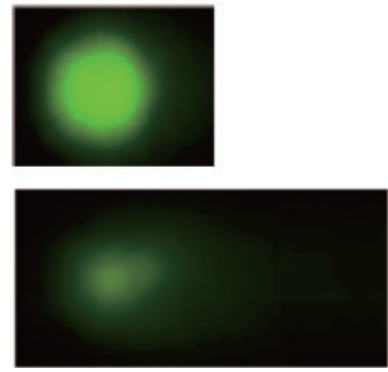

$300+C . C 10 \mu \mathrm{M}$

B
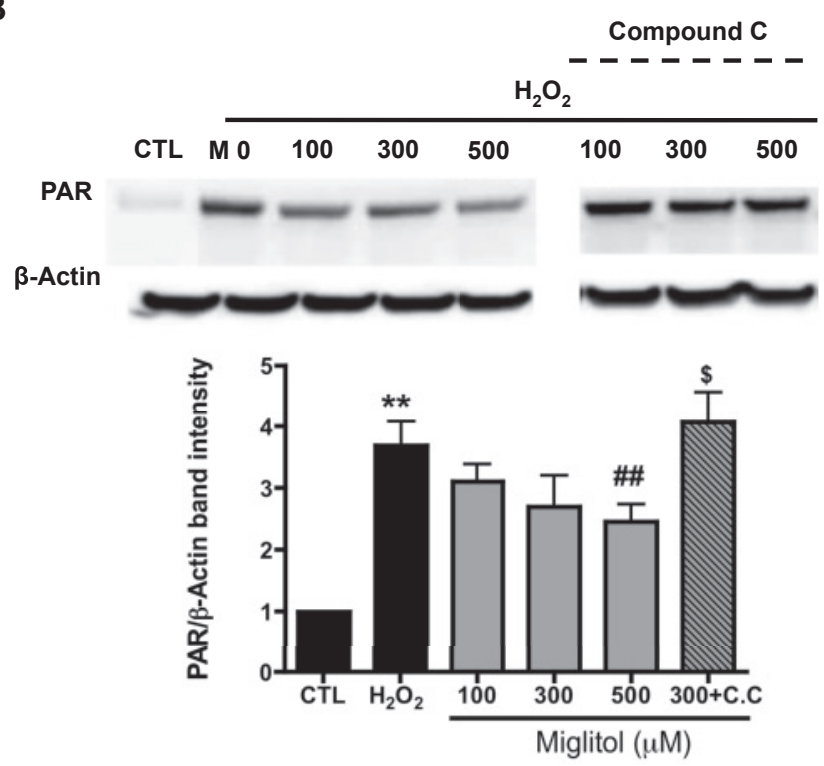

artery disease, and microvascular complications in patients with diabetes (22). Diabetes mellitus is known to

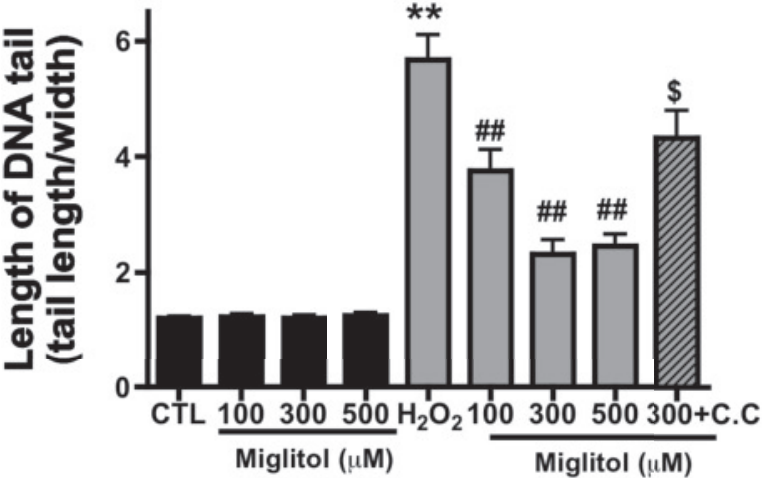

Fig. 3. Miglitol dose-dependently exerts cytoprotective effects against oxidative stress. A: DNA strand breakage in response to $\mathrm{H}_{2} \mathrm{O}_{2}$ in bEnd.3 cells was measured with the comet assay. $\mathrm{H}_{2} \mathrm{O}_{2}$ induced an increase in DNA strand breakage compared with CTL, and miglitol afforded a significant suppression of this response (left figure). The presence of Compound C (C.C) $(10 \mu \mathrm{M})$ alleviated the inhibitory effect of miglitol on DNA strand breakage. B: Activation of the nuclear enzyme poly(ADP-ribose) polymerase (PARP) was measured by detection of the poly(ADP ribose) polymers using western blotting. $\mathrm{H}_{2} \mathrm{O}_{2}$ induced an increase in PARP activation, and treatment of miglitol afforded a significant suppression of this response. The presence of C.C $(10 \mu \mathrm{M})$ alleviated the suppression of this response caused by miglitol treatment. ${ }^{* *} P<0.01$ vs. CTL, ${ }^{\#} P<0.01$ vs. $\mathrm{H}_{2} \mathrm{O}_{2},{ }^{\$} P<0.05$ vs. miglitol (300 $\mu \mathrm{M}) ; \mathrm{n}=4$.

increase vascular reactive oxygen species, resulting in DNA damage, endothelial dysfunction, and NO bioavail- 
A

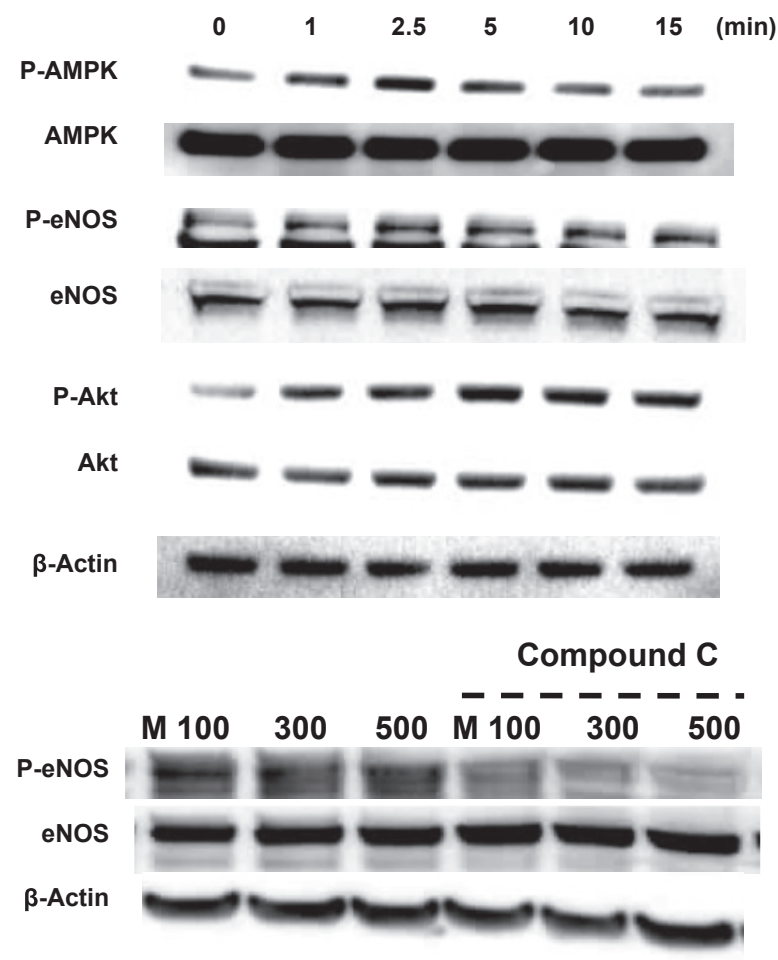

B

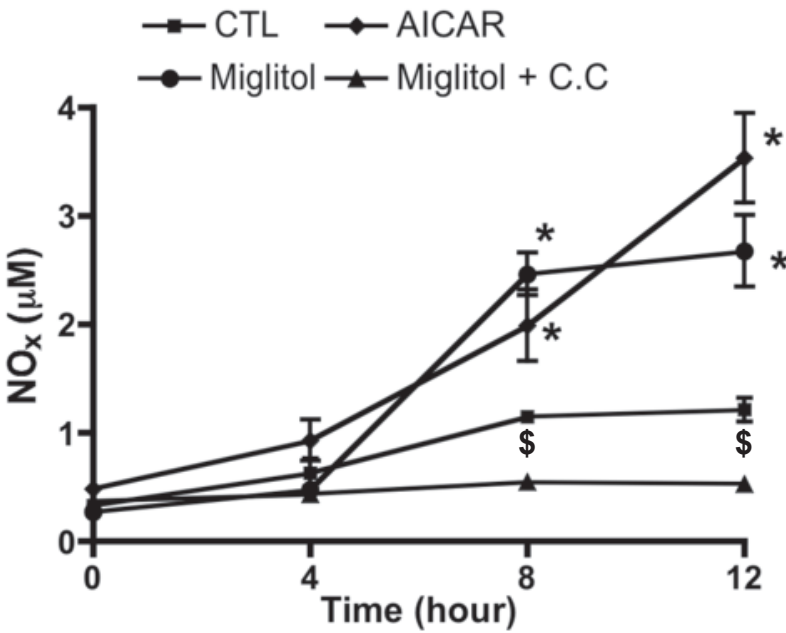

Fig. 4. Miglitol activates AMP-activated protein kinase (AMPK) and eNOS phosphorylation in bEnd.3 cells. A: Upper panel: The bEnd. 3 cells were treated with $300 \mu \mathrm{M}$ miglitol for the indicated time periods before they were lysed; the lysates were collected and then they were probed with antibodies specific for AMPK, Akt, endothelial nitric oxide synthase (eNOS), and their phosphorylated forms. Lower panel: eNOS phosphorylation was markedly suppressed after incubation with Compound C. Cells were pre-incubated with or without C.C $(10 \mu \mathrm{M})$ for $1 \mathrm{~h}$ and then, treated with miglitol of indicated concentration $(\mu \mathrm{M})$ for $5 \mathrm{~min}$. B: NO release has been accelerated by the incubation of miglitol, and it has been attenuated by the presence of compound C (C.C). Confluent bEnd. 3 cultures were incubated with 300 $\mu \mathrm{M}$ miglitol (circles), miglitol plus C.C (triangle), AICAR $(250 \mu \mathrm{M})$ as a positive control (diamond), and control (square) for the indicated time points. NO release at the indicated time points was measured using a NOx analyzing HPLC system. $* P<0.01$ vs. CTL, ${ }^{\$} P<0.05$ vs. miglitol; $n=4$. ability $(12,23)$. In addition, there may be a link between increased ROS formation and endothelial dysfunction in various forms of critical illnesses. ROS, such as hydrogen peroxide and peroxinitrite, might induce DNA damage and activation of the nuclear enzyme PARP (24).

In the present study, we investigated whether miglitol reduces cell death and DNA apoptosis by inhibiting ROS production by using the MTT reduction method, flow cytometry, comet assay, and determining the protein expression of PARP. These responses are known to be involved in development of atherosclerosis. We found that hydrogen peroxide was generated in these alterations in endothelial cells and that the treatment of miglitol restored all of these alterations, including cell death and DNA apoptosis.

Several mechanisms may account for association of endothelial dysfunction with NO bioavailability as a major factor. It is well known that NO synthesized from L-arginine by eNOS has protective effects on endothelial cell by its anti-proliferative and anti-inflammatory properties. At least in part, in the insulin-resistant state, NO level is reduced by inhibiting the phosphatidylinositol 3-kinase (PI3)-Akt-eNOS pathway by the stimulation of the AMPK-related signal transduction pathway (25).

In this study, we showed that the cytoprotetive effect of miglitol on endothelial cells was associated with the activation of AMPK via Akt phosphorylation and with increased NO production. It has been previously reported that Akt is phosphorylated and activated in AMPKactivated endothelial cells, and this activation induced bio-protective effects $(23,26,27)$. A previous study demonstrated that both the Akt signaling and the rate of production of NOx are important regulators of cell survival in endothelial cells $(23,26)$. It is true that miglitol can activate AMPK, since the extent of AMPK phosphorylation at Thr-172 strongly reflects its activity (28). Although we did not investigate whether Akt activation is PI3-kinase-dependent or not, in a previous study using a rabbit model of ischemia, the administration of miglitol up-regulated the myocardial expression of phospho (p)PI3 kinase and p-Akt, leading to a reduction in myocardial infarct size (29). It is also possible that the activation of NO/cGMP signaling by miglitol may be related to an inhibition of endothelial cell apoptosis under oxidative stress (30).

AICAR (a potent stimulator of AMPK), as a positive control, up-regulated the phosphorylation of eNOS and increased NO production. The upstream AMPK appears to exert the kinase activity of eNOS activation. On the other hand, C.C, an AMPK inhibitor, caused a markedly inhibition of AMPK expression and significantly attenuated miglitol-induced eNOS phosphorylation, eNOS activity, and NO production. Thus, miglitol may increase 
A
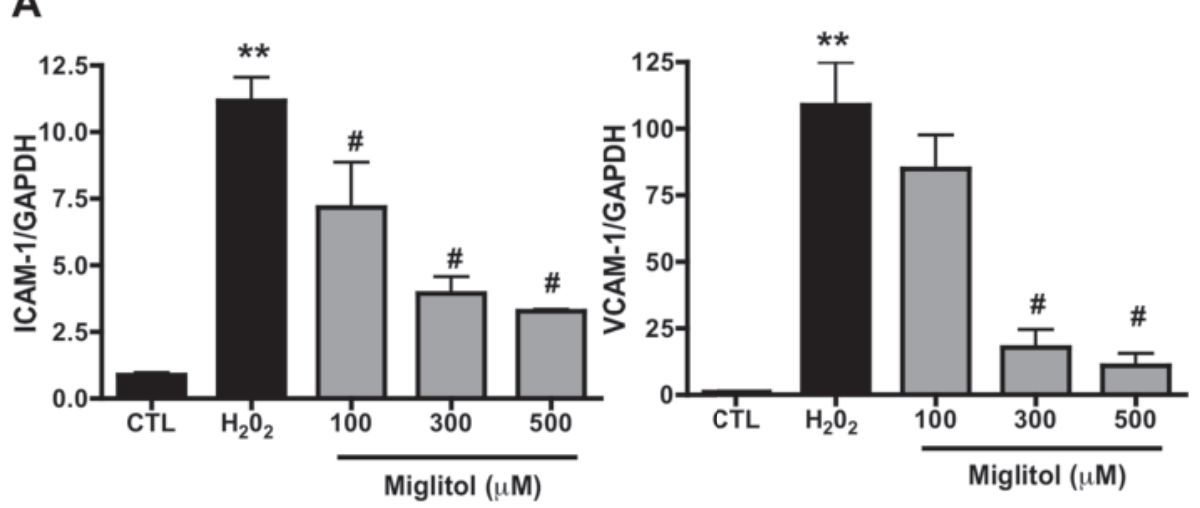

B

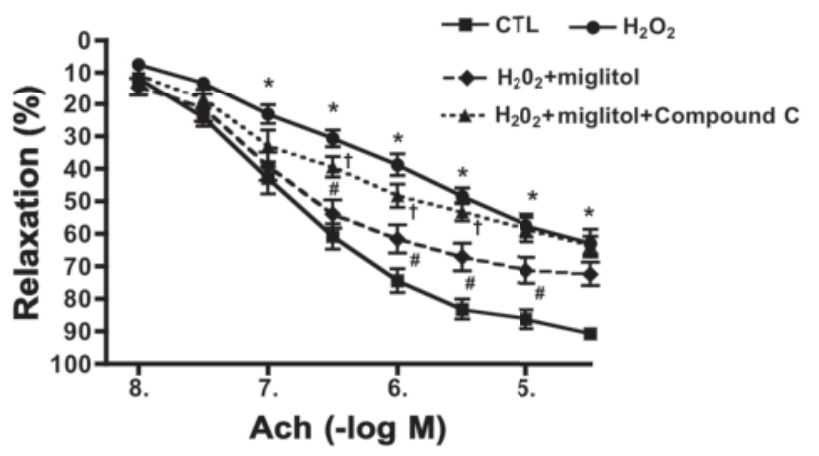

Fig. 5. Miglitol markedly diminishes the expression of VCAM-1 and ICAM-1 mRNA and improves endothelial function. A: Confluent bEnd. 3 cultures were pretreated with miglitol for $24 \mathrm{~h}$ and subjected to treatment with $\mathrm{H}_{2} \mathrm{O}_{2}(100 \mu \mathrm{M})$ for $6 \mathrm{~h}$. The expression of mRNA level was measured by real time PCR. Data are shown as the mean \pm S.E.M. values of $n=5$ experiments performed on different experimental days and are expressed as a ratio of glyceraldehyde-3-phosphate dehydrogenase (GAPDH). ${ }^{* *} P<0.01$ vs. CTL, ${ }^{*} P<0.05$ vs. $\mathrm{H}_{2} \mathrm{O}_{2} ; \mathrm{n}=5-6$. B: Miglitol protects against the development of endothelial dysfunction in rat aortic rings. Rat aortic rings were incubated in Krebs solution containing $\mathrm{H}_{2} \mathrm{O}_{2}(500 \mu \mathrm{M}), \mathrm{H}_{2} \mathrm{O}_{2}$ plus miglitol $(300 \mu \mathrm{M})$, or $\mathrm{H}_{2} \mathrm{O}_{2}$ plus miglitol $(300 \mu \mathrm{M})$ with compound $\mathrm{C}$ for $2 \mathrm{~h} . \mathrm{H}_{2} \mathrm{O}_{2}$ induced a suppression of endotheliumdependent relaxation $(* P<0.05)$. This effect was prevented by miglitol. The presence of Compound $\mathrm{C}(100 \mu \mathrm{M})$ alleviated the suppression of this response caused by treatment with miglitol. $* P<0.05$ vs. CTL, ${ }^{\sharp} P<0.05$ vs. $\mathrm{H}_{2} \mathrm{O}_{2},{ }^{\dagger} P<0.05$ vs. $\mathrm{H}_{2} \mathrm{O}_{2}$ plus miglitol; $\mathrm{n}=4-5$ each vascular ring.
eNOS phosphorylation and NO production through the activation of AMPK.

We also demonstrated that miglitol concentrationdependently inhibits oxidative stress-induced VCAM-1 and ICAM-1 mRNA expression. These data suggest that AMPK activation by miglitol might inhibit NF- $\kappa$ B activation and subsequently attenuate the mRNA expression of ICAM-1 and VCAM-1. A previous study demonstrated that the expression of eNOS and the production of NO in endothelial cells, which is produced by the interaction with the oxidative balance of the cells, potently inhibit endothelial cell apoptosis via inhibiting the expression of transcription factor NF- $\kappa \mathrm{B}$ which can upregulate the expression of inflammatory cytokines and adhesion molecules (31). Thus, this inhibitory effect of miglitol on the mRNA expression of ICAM-1 and VCAM-1 might be associated with the inhibition of the activation of NF- $\kappa \mathrm{B}$ by oxidative stress.

With respect to vascular studies employing in vitro exposure to oxidative stress, aortic rings with co-incubation of miglitol significantly restored endothelial-dependent vasodilation. In contrast, C.C inhibited the effect of miglitol on the endothelial cells. These data are consistent with our in vitro findings in endothelial cells.

In conclusion, the present study demonstrated that miglitol inhibits endothelial cell injury and protects against DNA damage from intensive oxidative stress. This mechanism may be involved in the activation of AMPK in endothelial cells, resulting in increased NO production and reduced ICAM-1 and VCAM-1 mRNA expression. Since we did not investigate the effects of miglitol on the pathway of caspase or MAP kinase, it should be interpreted cautiously that the main effect of miglitol on endothelial cells is mediated by the activation of AMPK. Furthermore, co-incubation of aortic rings with miglitol significantly restored impairment of endothelial-dependent vasodilation under oxidative stress. This effect on the endothelium might be associated with AMPK activation and subsequent NO production.

\section{Acknowledgments}

This study was supported by Dokkyo Medical University, Investigator-Initiated Research Grant no. 2008-01-2 (to K.S.). We thank Sanwa Kagaku Kenkyusho Co., Ltd. (Nagoya), for the generous gift of miglitol. We are grateful to Dr. Manaka (Institute for Medical Science, Dokkyo Medical University) for NOx measurement and Dr. Akimoto for cell culture. 


\section{References}

1 Davignon J, Ganz P. Role of endothelial dysfunction in atherosclerosis. Circulation. 2004;109:III27-III32.

2 Giacco F, Brownlee M. Oxidative stress and diabetic complications. Circ Res. 2010;107:1058-1070.

3 Szabo C. Role of nitrosative stress in the pathogenesis of diabetic vascular. dysfunction. Br J Pharmacol. 2009;156:713-727.

4 Yung LM, Leung FP, Yao X, Chen ZY, Huang Y. Reactive oxygen species in vascular wall. Cardiovasc Hematol Disord Drug Targets. 2006;6:1-19.

5 Nishikawa T, Edelstein D, Du XL, Yamagishi S, Matsumura T, Kaneda Y, et al. Normalizing mitochondrial superoxide production blocks three pathways of hyperglycaemic damage. Nature. 2000;404:787-790.

6 Du X, Matsumura T, Edelstein D, Rossetti L, Zsengellér Z, Szabó $\mathrm{C}$, et al. Inhibition of GAPDH activity by poly(ADP-ribose) polymerase activates three major pathways of hyperglycemic damage in endothelial cells. J Clin Invest. 2003;112:1049-1057.

7 Hulin B. New hypoglycaemic agents. Prog Med Chem. 1994; 31:1-58.

8 Pagano G, Marena S, Corgiat-Mansin L, Cravero F, Giorda C, Bozza M, et al. Comparison of miglitol and glibenclamide in diettreated type 2 diabetic patients. Diabetes Metab. 1995;21: 162-167.

9 Bischoff H. Pharmacology of alpha-glucosidase inhibition. Eur J Clin Invest. 1994;24:3-10.

10 Axen KV, Li X, Sclafani A. Miglitol (BAY m 1099) treatment of diabetic hypothalamic-dietary obese rats improves islet response to glucose. Obes Res. 1999;7:83-89.

11 Russell JC, Graham SE, Dolphin PJ. Glucose tolerance and insulin resistance in the JCR: LA-corpulent rat: effect of miglitol (Bay m1099). Metabolism. 1999;48:701-706.

12 Wang N, Minatoguchi S, Chen X, Uno Y, Arai M, Lu C, et al. Antidiabetic drug miglitol inhibits myocardial apoptosis involving decreased hydroxyl radical production and Bax expression in an ischaemia/reperfusion rabbit heart. Br J Pharmacol. 2004; 142:983-990

13 Oláh G, Módis K, Gero D, Suzuki K, Dewitt D, Traber DL, et al. Cytoprotective effect of $\gamma$-tocopherol against tumor necrosis factor $\alpha$ induced cell dysfunction in L929 cells. Int J Mol Med. 2011;28:711-720.

14 Ozsvári B, Puskás LG, Nagy LI, Kanizsai I, Gyuris M, Madácsi $\mathrm{R}$, et al. A cell-microelectronic sensing technique for the screening of cytoprotective compounds. Int J Mol Med. 2010;25: 525-530.

15 Mukhopadhyay P, Rajesh M, Yoshihiro K, Haskó G, Pacher P. Simple quantitative detection of mitochondrial superoxide production in live cells. Biochem Biophys Res Commun. 2007; 358:203-208.

16 Robinson KM, Janes MS, Pehar M, Monette JS, Ross MF, Hagen TM, et al. Selective fluorescent imaging of superoxide in vivo using ethidium-based probes. Proc Natl Acad Sci U S A. 2006; 103:15038-15043.

17 Koike A, Nishikawa H, Wu W, Okada Y, Venkitaraman AR, Ohta T. Recruitment of phosphorylated NPM1 to sites of DNA damage through RNF8-dependent ubiquitin conjugates. Cancer Res. 2010;70:6746-6756.

18 Jojima T, Suzuki K, Hirama N, Uchida K, Hattori Y. Glimepiride upregulates eNOS activity and inhibits cytokine-induced NFkappaB activation through a phosphoinoside 3-kinase-Aktdependent pathway. Diabetes Obes Metab. 2009;11:143-149.

19 Suzuki K, Uchida K, Nakanishi N, Hattori Y. Cilostazol activates AMP-activated protein kinase and restores endothelial function in diabetes. Am J Hypertens. 2008;21:451-457.

20 Zhu CB, Carneiro AM, Dostmann WR, Hewlett WA, Blakely RD. p38 MAPK activation elevates serotonin transport activity via a trafficking-independent, protein phosphatase 2A-dependent process. J Biol Chem. 2005;280:15649-15658.

21 Wong CM, Yung LM, Leung FP, Tsang SY, Au CL, Chen ZY, et al. Raloxifene protects endothelial cell function against oxidative stress. Br J Pharmacol. 2008;155:326-334.

22 Hashimoto K, Minatoguchi S, Hashimoto Y, Wang N, Qiu X, Yamashita K, et al. Role of protein kinase C, K(ATP) channels and DNA fragmentation in the infarct size-reducing effects of the free radical scavenger T-0970. Clin Exp Pharmacol Physiol. 2001;28:193-199.

23 Nagata D, Mogi M, Walsh K. AMP-activated protein kinase (AMPK) signaling in endothelial cells is essential for angiogenesis in response to hypoxic stress. J Biol Chem. 2003;278: 31000-31006.

24 Garcia Soriano F, Virág L, Jagtap P, Szabó E, Mabley JG, Liaudet L, et al. Diabetic endothelial dysfunction: the role of poly(ADPribose) polymerase activation. Nat Med. 2001;7:108-113.

25 Han L, Yu Y, Sun X, Wang B. Exendin-4 directly improves endothelial dysfunction in isolated aortas from obese rats through the cAMP or AMPK-eNOS pathways. Diabetes Res Clin Pract. 2012. [Epub ahead of print].

26 Ouchi N, Kobayashi H, Kihara S, Kumada M, Sato K, Inoue T, et al. Adiponectin stimulates angiogenesis by promoting crosstalk between AMP-activated protein kinase and Akt signaling in endothelial cells. J Biol Chem. 2004;279:1304-1309.

27 Levine YC, Li GK, Michel T. Agonist-modulated regulation of AMP-activated protein kinase (AMPK) in endothelial cells. Evidence for an AMPK -> Rac1 -> Akt -> endothelial nitric-oxide synthase pathway. J Biol Chem. 2007;282:20351-20364.

28 Hardie DG. The AMP-activated protein kinase pathway--new players upstream and downstream. J Cell Sci. 2004;117: 5479-5487.

29 Iwase M, Yamada Y, Kobayashi H, Yasuda S, Kawamura I, Sumi $\mathrm{S}$, et al. Both stimulation of GLP-1 receptors and inhibition of glycogenolysis additively contribute to a protective effect of oral miglitol against ischaemia-reperfusion injury in rabbits. $\mathrm{Br} \mathrm{J}$ pharmacol. 2011;164:119-131.

30 Roberts DD, Miller TW, Roger NM, Yao M, Isenberg JS. The matricellular protein thrombospondin-1 globally regulates cardiovascular function and responses to stress via CD47. Matrix Biol. 2012;31:162-169.

31 Dimmeler S, Hermann C, Galle J, Zeiher AM. Upregulation of superoxide dismutase and nitric oxide synthase mediates the apoptosis-suppressive effects of shear stress on endothelial cells. Arterioscler Thromb Vasc Biol. 1999;19:656-664. 